Article

\title{
Effect of Amphiphilic Polymer/Nano-Silica Composite on Shale Stability for Water-Based Muds
}

\author{
Zhengsong Qiu ${ }^{1, *}$, Jiangen $\mathrm{Xu}{ }^{1}{ }^{1 *}$, Peng Yang ${ }^{2}$, Xin Zhao ${ }^{1}$, Tingbo Mou ${ }^{1}$, Hanyi Zhong ${ }^{1}$ and \\ Weian Huang ${ }^{1}$
}

1 School of Petroleum Engineering, China University of Petroleum (East China), Qingdao 266580, China; zhaoxin@upc.edu.cn (X.Z.); moutingbo@outlook.com (T.M.); zhonghanyi@126.com (H.Z.); masterhuang1997@163.com (W.H.)

2 Engineering Research Institute, CNPC Great Wall Drilling Engineering Company Limited, Panjin 124010, China; yangpeng00625@163.com

* Correspondence: qiuzs@upc.edu.cn (Z.Q.); xujiangen0@163.com (J.X.); Tel.: +86-53286983576 (Z.Q.); +86-18561892069 (J.X.)

Received: 20 September 2018; Accepted: 2 October 2018; Published: 7 October 2018

\begin{abstract}
Research on using nanotechnology to solve shale instability problems in drilling engineering has been increasing. The combination of amphiphilic polymer and silica nanoparticles may be a new way to improve shale stability. Herein, an amphiphilic polymer/nano-silica composite (poly(styrene-methyl methacrylate-acrylamide) $/$ nano- $\mathrm{SiO}_{2}$ ) was introduced as a novel shale stabilizer $\mathrm{SMA} / \mathrm{SiO}_{2}$ for water-based muds, which possessed the advantages of both physical plugging and chemical inhibition during the drilling operations. The $\mathrm{SMA} / \mathrm{SiO}_{2}$ was prepared and characterized by Fourier transform infrared spectra (FT-IR), nuclear magnetic resonance $\left({ }^{1} \mathrm{H}-\mathrm{NMR}\right)$, transmission electron microscope (TEM), particle size distribution (PSD) and thermogravimetric analysis (TGA) experiments, which confirmed that $\mathrm{SMA} / \mathrm{SiO}_{2}$ was regularly spherical with nano-scale and showed good high-temperature resistance. To evaluate the plugging capacity of $\mathrm{SMA} / \mathrm{SiO}_{2}$, the pressure transmission test and BET analysis were applied. The results indicated $\mathrm{SMA} / \mathrm{SiO}_{2}$ was capable of effectively plugging the pores and fractures in shale. To evaluate the hydration inhibition capacity of $\mathrm{SMA} / \mathrm{SiO}_{2}$, the rolling dispersion experiment and contact angle test were adopted. The results demonstrated that $\mathrm{SMA} / \mathrm{SiO}_{2}$ could reduce the tendency of shale hydration, which was better than potassium chloride $(\mathrm{KCl})$ and polymeric alcohol $(\mathrm{JHC})$. In addition, $\mathrm{SMA} / \mathrm{SiO}_{2}$ only created slight variations on the rheological parameters of the water-based muds (WBMs) and showed a significant filtration control performance. Due to the outstanding performance of physical plugging and chemical inhibition, $\mathrm{SMA} / \mathrm{SiO}_{2}$ was expected to be a novel shale stabilizer to solve shale instability problems.
\end{abstract}

Keywords: shale stabilizer; amphiphilic polymer; nano-SiO${ }_{2}$; plugging ability; hydration inhibition

\section{Introduction}

Drilling fluids are considered as circulating fluids in the drilling operations, which provide multiple functions. Their major functions consist of suspending/transporting drill cuttings, cooling and lubricating the drilling bits, maintaining borehole stability and reducing the formation damage [1-3]. Drilling fluids are usually grouped into three types: water-based muds (WBMs), oil-based muds, and synthetic-based muds. Due to their lower cost and lesser impact on environment, WBMs have become the most widely used drilling fluids in the world [4,5].

In recent years, the development of shale gas as an unconventional oil and gas resource has gained an increase in attention [6-12]. The technology of drilling fluids for the long well section of a horizontal well is one of the key technologies used to drill shale gas formations. Since the shale 
formations develop nano-scale pores and fractures and have a strong water-sensitivity characteristic, shale instability in the drilling process is prone to occur. This restricts the process of shale gas exploration and development $[13,14]$. Figure 1 shows the general sketch of the shale instability problems caused by WBMs. Due to a large number of nano-scale pores and fractures developed in the shale formations, they are characterized by extremely low permeability and low porosity [15-17]. In the drilling operations, pressure transmission in WBMs will result in an increase in the pore pressure of shale formations, and thus cause wellbore instability. The best approach for solving this problem is to plug the nano-scale pores and fractures developed in the shale formations [18-20]. However, conventional agents for WBMs are too large to play an effective role of plugging. Therefore, seeking for plugging agents with a suitable size to achieve better plugging capacity is essential.

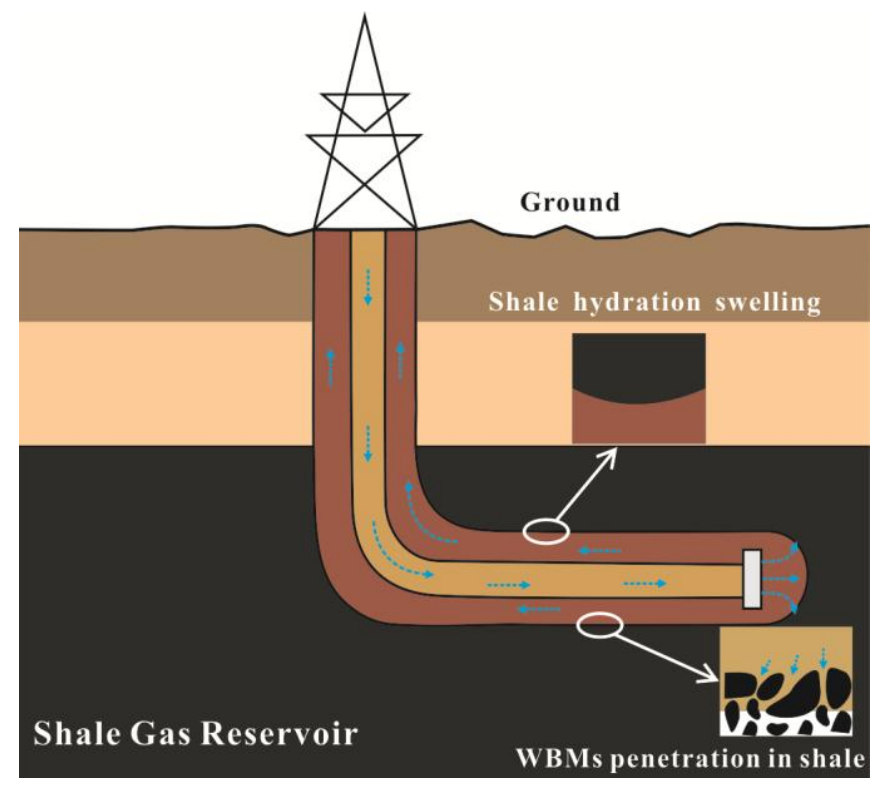

Figure 1. General sketch of the shale instability problems caused by WBMs (water-based muds).

In the last few years, the interest in using nanotechnology in the oil and gas industry has been increasing [21-23]. Various kinds of nanomaterials have been introduced into WBMs as promising shale stabilizers [24-26]. The inorganic nanoparticles such as unmodified nanosilica were first introduced into WBMs as plugging agents. It was found that nanosilica could seal the shale pores and improve the filtration loss performance of WBMs $[27,28]$. Graphene oxide has also been investigated as another form of rigid nanoparticles, and it showed good plugging performance in WBMs [29]. However, inorganic nanoparticles are prone to aggregation, and thus the plugging ability can be weakened. Polymeric nanoparticles (such as polymer latex) possessing better dispersing performance in WBMs have also been introduced as plugging agents. The studies showed that the polymeric nanoparticles could decrease shale permeability and effectively retard pressure transmission [30,31]. However, polymer latex is usually preserved in the emulsion state and sensitive to the environmental change, which restrict its application to oilfields. Recently, polymer-inorganic nanocomposites have attracted more and more attention in the drilling fluids industry [32-35]. The benefits of nanocomposites to be applied in WBMs include excellent dispersing performance, decrease in filtration volume, and improvement of rheological properties [36,37]. Therefore, the polymer-inorganic nanocomposites may be an effective way to solve shale instability problems.

Polyacrylamide-grafted-polyethylene glycol/silica nanocomposite was reported as a potential additive for WBMs, which demonstrated good shale hydration inhibition performance [28]. But the plugging capacity was not considered in their work. Poly(AM-AMPS)/nano- $\mathrm{SiO}_{2}$ composite was introduced into WBMs as a fluid loss agent [26]. Research showed that the composite could plug the nanopores of shale, but the shale hydration inhibition performance was not further evaluated. 
Since shales mainly consist of clay minerals, shale hydration becomes another important factor causing borehole instability that cannot be ignored [38-40]. Amphiphilic polymer has been reported to be able to inhibit shale hydration [41]. The combination of amphiphilic polymer and silica nanoparticles may have the advantages of both physical plugging and chemical inhibition. In this study, a novel shale stabilizer poly(St-MMA-AM)/nano-SiO 2 composite $\left(\mathrm{SMA} / \mathrm{SiO}_{2}\right)$ was synthesized. Poly(St-MMA-AM) was used as an amphiphilic polymer where St and MMA provided the hydrophobic segments and AM provided the hydrophilic segments.

First, materials and methods were presented. Then, the novel shale stabilizer $\mathrm{SMA} / \mathrm{SiO}_{2}$ was prepared and characterized. To investigate the plugging ability of $\mathrm{SMA} / \mathrm{SiO}_{2}$, the pressure transmission experiment and BET analysis were conducted. To evaluate the shale hydration inhibition capacity of $\mathrm{SMA} / \mathrm{SiO}_{2}$, the rolling dispersion experiment and contact angle test were carried out. Finally, the compatible test was conducted to evaluate the effect of $\mathrm{SMA} / \mathrm{SiO}_{2}$ on the rheological and filtration control properties of the WBMs.

\section{Materials and Methods}

\subsection{Materials}

Styrene (St, 99\%), methyl methacrylate (MMA, 98\%), acrylamide (AM, 98\%), potassium chloride $(\mathrm{KCl}, 99.5 \%)$, ethanol (99.7\%), sodium dodecyl sulfate (SDS), 3-methacryloxypropyltrimethoxysilane (KH570, 98\%), ethylic acid (99.5\%) and potassium persulfate (KPS, 99\%) were obtained from Sinopharm Chemical Reagent Co., Ltd., Shanghai, China and used without further purification. KH570 was mainly used to improve the bonding properties of organic and inorganic materials. Nano-silica particles $(99.8 \%$, $7-42 \mathrm{~nm}$ ) and octylphenol polyoxyethylene ether (OP-10, 99\%) were purchased from Aladdin Reagent Co., Ltd., Shanghai, China and used as received. The TEM (JEM-2100UHR, JEOL Ltd., Akishima, Tokyo, Japan) image and the particle size distribution (PSD) curve of nano-silica particles was shown in Figure 2. The particle size of nano-silica particles was mainly distributed in the range of 7-18 nm. Due to a few nanoparticles agglomerated, the larger particles were found in $32-42 \mathrm{~nm}$. Polymeric alcohol (JHC) was provided by China Oilfield Services (Sanhe, China). Sodium bentonite was provided by Weifang Huawei Bentonite Group Co., Ltd., Weifang, China. Xanthan gum and low-viscosity polyanionic celluloses were obtained from Shida Chuangxin Technology Co., Ltd., Dongying, China. Furthermore, deionized water was used during the experiments. The shale samples used in this work were provided by Turpan Hami Basin, China and the X-ray diffraction analysis results were shown in Table 1.
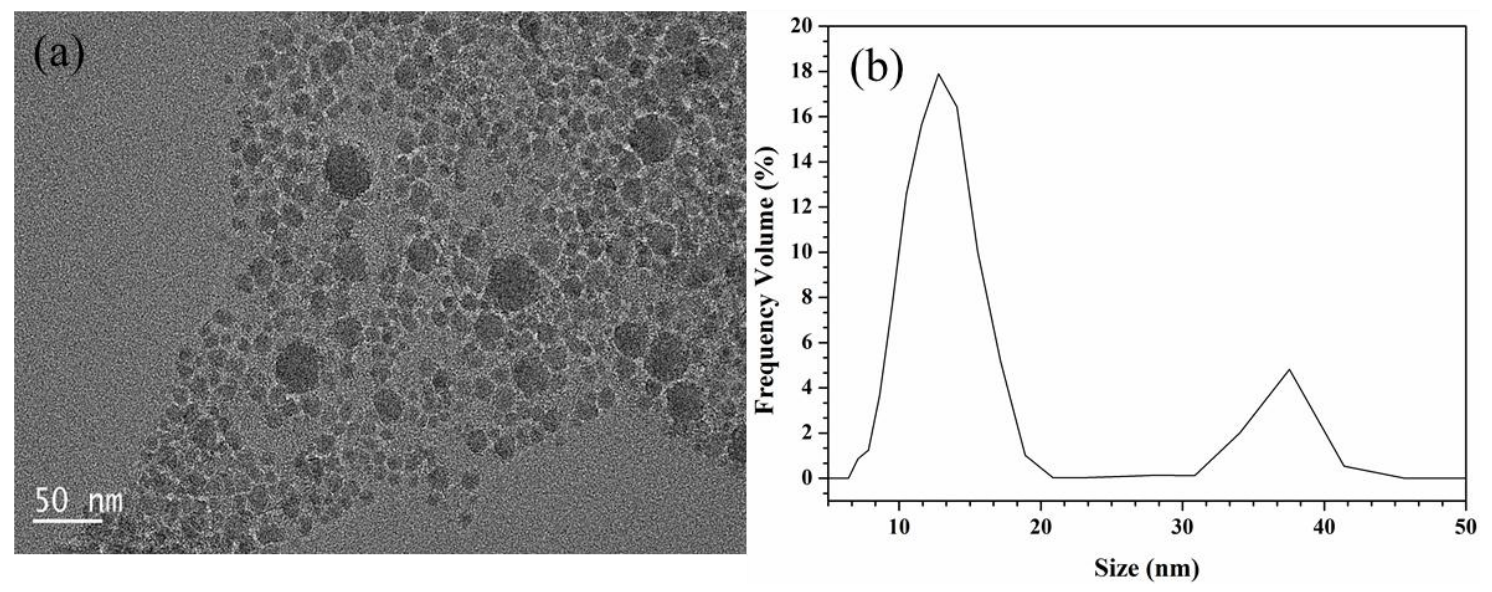

Figure 2. (a) TEM (transmission electron microscope) image and (b) PSD (particle size distribution) curve of nano-silica particles. 
Table 1. Mineral content of the shale samples.

\begin{tabular}{cccc}
\hline Component & Content (wt \%) & Component of Clay Mineral & Content (wt \%) \\
\hline Quartz & 20 & Illite & 12 \\
Calcite & 28 & Chlorite & 3 \\
Plagioclase & 29 & Kaolinite & 3 \\
Iron dolomite & 2 & Illite/smectite mixed layer & 82 \\
Potassium feldspar & 6 & & \\
Clay mineral & 15 & & \\
\hline
\end{tabular}

\subsection{Preparation of $\mathrm{SMA} / \mathrm{SiO}_{2}$}

The novel shale stabilizer $\mathrm{SMA} / \mathrm{SiO}_{2}$ was prepared based on the following two stages. The first stage was to prepare $\mathrm{KH} 570 / \mathrm{SiO}_{2}$ nanoparticles. Firstly, nano-silica particles (4 g) were dispersed into ethanol $(60 \mathrm{~mL})$ at $25{ }^{\circ} \mathrm{C}$ under ultrasonic conditions. Then, $\mathrm{KH} 570(0.8 \mathrm{~g})$ was dissolved in ethanol $/ \mathrm{H}_{2} \mathrm{O}$ dispersion and the dispersion was adjusted to $\mathrm{pH}=4$ with ethylic acid. Secondly, the above dispersions were mixed in the reactor and stirred at $75{ }^{\circ} \mathrm{C}$ for $4 \mathrm{~h}$. Thirdly, the obtained $\mathrm{KH} 570 / \mathrm{SiO}_{2}$ nanoparticles were purified several times by centrifugation and washing treatment using ethanol. Figure 3 shows the schematic representation on the silane functionalization of $\mathrm{SiO}_{2}$.

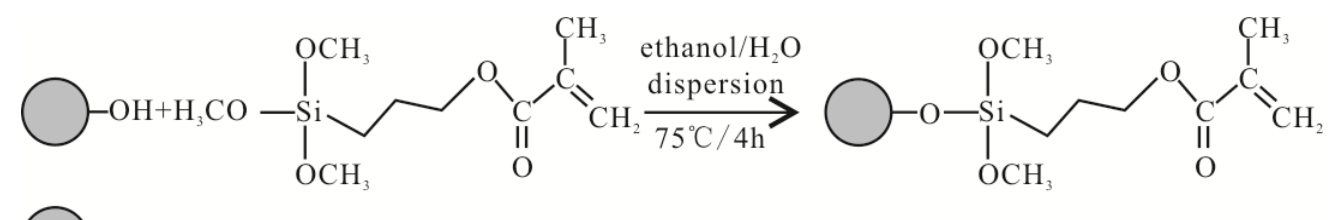
nano- $\mathrm{SiO}_{2}$

Figure 3. Schematic representation on the silane functionalization of $\mathrm{SiO}_{2}$.

The second stage was to prepare the novel shale stabilizer $\mathrm{SMA} / \mathrm{SiO}_{2}$ with $\mathrm{St}, \mathrm{MMA}, \mathrm{AM}$ and $\mathrm{KH} 570 / \mathrm{SiO}_{2}$ nanoparticles through emulsion polymerization [42]. Firstly, $\mathrm{KH} 570 / \mathrm{SiO}_{2}$ nanoparticles $(0.4 \mathrm{~g})$ were added to the monomer mixture containing St (12 g), MMA (6 g) and AM (2 g), and the mixture was ultrasonically treated for $3 \mathrm{~h}$. Then, the aqueous solutions consisting of deionized water $(60 \mathrm{~mL})$, SDS $(0.1 \mathrm{~g})$, and OP-10 $(0.1 \mathrm{~g})$ were added to the mixture, and pre-emulsified under vigorous stirring. Secondly, the pre-emulsion was transferred in a $250 \mathrm{~mL}$ flask and the temperature was maintained at $75{ }^{\circ} \mathrm{C}$ for $30 \mathrm{~min}$. Thirdly, the aqueous solutions containing of KPS $(0.12 \mathrm{~g})$ was poured to the flask for inducing polymerization and the polymerization was left for $3 \mathrm{~h}$. The solid product was obtained by centrifugation and washing treatment using ethanol $/ \mathrm{H}_{2} \mathrm{O}$, and dried at $60{ }^{\circ} \mathrm{C}$ under vacuum condition for further use.

\subsection{Characterization of $\mathrm{SMA} / \mathrm{SiO}_{2}$}

Fourier transform infrared spectra (FT-IR) of $\mathrm{SiO}_{2}, \mathrm{KH} 570 / \mathrm{SiO}_{2}$ and $\mathrm{SMA} / \mathrm{SiO}_{2}$ were obtained by a FT-IR spectrometer (Nicolet 6700, Thermo Scientific, Waltham, MA, USA.). The nuclear magnetic resonance $\left({ }^{1} \mathrm{H}-\mathrm{NMR}\right)$ spectrum of $\mathrm{SMA} / \mathrm{SiO}_{2}$ was determined by an NMR spectrometer (Bruker AV500, BRUKER OPTICS, Karlsruhe, Germany), and the sample was dissolved in $\mathrm{CDCl}_{3}$. The particle size distribution (PSD) of $\mathrm{SMA} / \mathrm{SiO}_{2}$ in aqueous solution was measured with a particle size analyzer (NanoBrook Omni, Brookhaven Instruments Corporation, Holtsville, NY, USA.). The morphology of $\mathrm{SMA} / \mathrm{SiO}_{2}$ in aqueous solution was recorded by a transmission electron microscope (TEM, JEM-2100UHR, JEOL Ltd., Akishima, Tokyo, Japan). The thermogravimetric analysis (TGA) of $\mathrm{SMA} / \mathrm{SiO}_{2}$ was carried out on a TGA/DTA thermogravimetric analyzer (NETZSCH 209F3, Netzsch Group, Selb, Germany). During the experiment, the heating rate was set at $10{ }^{\circ} \mathrm{C} / \mathrm{min}$ under a $\mathrm{N}_{2}$ atmosphere, while the heating range was set at $25-600^{\circ} \mathrm{C}$. 


\subsection{Pressure Transmission Test}

The pressure transmission technology provides a scientific and effective method to evaluate the plugging performance of different fluids. A shale hydra-mechanics coupling simulation test device developed by China University of Petroleum (East China) was used for the pressure transmission experiment [43]. In this test, the shale samples were cut into cylindrical cores (diameter: $2.54 \mathrm{~cm}$; length: $0.75 \mathrm{~cm}$ ). Base fluid for the test was prepared by dispersing $4 \mathrm{~g}$ sodium bentonite into $100 \mathrm{~mL}$ distilled water. Firstly, the shale core was placed into the core holder, and the axial and confining pressure were set at $5 \mathrm{MPa}$ during the experiment. Then, the test fluids were pumped into the upstream entrance to contact with the shale core, while the upstream pressure was maintained at $2 \mathrm{MPa}$ and the downstream's initial pressure was set at $1 \mathrm{MPa}$. The pressure transmission curve was recorded through monitoring the downstream pressure change. Furthermore, the permeability of shale cores before and after being plugged with $\mathrm{SMA} / \mathrm{SiO}_{2}$ could be calculated by the Equation (1) [44].

$$
K=\frac{\mu \beta V L}{A} \frac{\ln \left(\frac{P_{m}-P_{o}}{P_{m}-P\left(L, t_{2}\right)}\right)-\ln \left(\frac{P_{m}-P_{o}}{P_{m}-P\left(L, t_{1}\right)}\right)}{t_{2}-t_{1}}
$$

The equation describes the shale permeability $(K)$ as a function of viscosity $(\mu)$, static compression ratio $(\beta)$, enclosed volume $(V)$, length $(L)$, cross-sectional area $(A)$, experimental time $(t)$, upstream pressure $\left(P_{m}\right)$, initial downstream pressure $\left(P_{o}\right)$ and real-time downstream pressure $(P(L, t))$.

In addition, the morphology of the shale cores before and after being plugged with $\mathrm{SMA} / \mathrm{SiO}_{2}$ were observed by scanning electron microscopy (SEM) to investigate the plugging mechanism.

\subsection{Pore Structure Characterization of Shale}

BET analysis is a widely applied method to characterize pore structure characteristics of shale $[45,46]$. Shale cuttings were screened and crumbled between 40 mesh and 60 mesh. Then, the shale samples were soaked in deionized water and $1 \% \mathrm{SMA} / \mathrm{SiO}_{2}$ solutions respectively for $6 \mathrm{~h}$ at room temperature. After that they were removed from the solutions and dried in the air. Finally, nitrogen adsorption experiments were carried out on Quadrasorb SI equipment (Quantachrome Company, Boynton Beach, FL, USA). The surface area and pore volume of shale samples could be determined by analyzing the nitrogen adsorption data through BET analysis.

\subsection{Rolling Dispersion Experiment}

Rolling dispersion experiment was adopted to evaluate the hydration inhibition performance of $\mathrm{SMA} / \mathrm{SiO}_{2}$. In this test, shale cuttings were screened and crumbled into sizes in the range of $2.00-3.35 \mathrm{~mm}$, which were dried at $105^{\circ} \mathrm{C}$ for $4 \mathrm{~h}$. Then, $50 \mathrm{~g}$ of dried shale cuttings and $350 \mathrm{~mL}$ of inhibitor solutions were transferred to the aging tank. The aging tanks were put into the roller furnace and hot-rolled at the temperature of $77^{\circ} \mathrm{C}$ for $16 \mathrm{~h}$. After cooling, shale cuttings were washed with distilled water and filtrated by a 40-mesh sieve. Finally, the recovered shale cuttings were dried and weighed to calculate the shale recovery rate.

\subsection{Contact Angle Test}

The contact angle test was carried out to evaluate the effect of $\mathrm{SMA} / \mathrm{SiO}_{2}$ on the wettability of the shale surface. In brief, the shale surface was polished using sandpaper to make it smooth. Then, the shale samples were soaked in the $\mathrm{SMA} / \mathrm{SiO}_{2}$ solutions at different concentrations for $6 \mathrm{~h}$. After that they were removed from the solutions and dried in the air. Finally, a syringe was used to put a drop of water onto the shale surface and the images were recorded by the camera. The contact angle could be calculated by analyzing the images using built-in software. The contact angle measurement was conducted on the JC2000D5M contact angle meter (Zhongchen Company, Shanghai, China) at room temperature. 


\subsection{Compatible Test}

The compatible test was conducted to evaluate the effect of $\mathrm{SMA} / \mathrm{SiO}_{2}$ on the rheological and filtration control properties of the WBMs. The WBMs were prepared by mixing $4 \%$ pre-hydrated sodium bentonite muds, $1 \%$ low-viscosity polyanionic celluloses, $0.2 \%$ xanthan gum and $3 \%$ potassium chloride under high-speed $(8000 \mathrm{rpm})$ stirring conditions for $20 \mathrm{~min}$. Then, the WBMs were transferred into an ageing oven (Haitongda Company, Qingdao, China) and hot-rolled at the temperature of $120^{\circ} \mathrm{C}$ for $16 \mathrm{~h}$. After being hot-rolled, the rheological and filtration control properties of the WBMs were measured. The compatibility of $\mathrm{SMA} / \mathrm{SiO}_{2}$ in $\mathrm{WBMs}$ was evaluated by comparing the rheological and filtration control performance of WBMs with or without $\mathrm{SMA} / \mathrm{SiO}_{2}$.

The rheological parameters such as apparent viscosity (AV), plastic viscosity (PV), and yield point (YP) were measured based on the API-recommended standard procedure by ZNN-D6 rotating viscometers (Haitongda Company, Qingdao, China). The Equations (2)-(4) were used to calculate the rheological parameters according to the readings from the high rotational speeds (300 and $600 \mathrm{rpm}$ ). The fluid loss (FL $\mathrm{FLI}_{\mathrm{AP}}$ ) of the WBMs was tested on ZNS-2A filtration apparatus (Haitongda Company, Qingdao, China).

$$
\begin{gathered}
\text { Apparent Viscosity }(\mathrm{AV})=\Phi 600 / 2(\mathrm{mPa} \cdot \mathrm{s}) \\
\text { Plastic Viscosity }(\mathrm{PV})=\Phi 600-\Phi 300(\mathrm{mPa} \cdot \mathrm{s}) \\
\text { Yield Point }(\mathrm{YP})=(\Phi 300-\mathrm{PV}) / 2(\mathrm{~Pa})
\end{gathered}
$$

\section{Results and Discussion}

\subsection{Characterization of the $\mathrm{SMA} / \mathrm{SiO}_{2}$}

Figure 4 depicts FT-IR spectra of $\mathrm{SiO}_{2}, \mathrm{KH} 570 / \mathrm{SiO}_{2}$ and $\mathrm{SMA} / \mathrm{SiO}_{2}$, and the characteristic peaks were observed. As shown in Figure $4 \mathrm{a}$, the stretching band of $\mathrm{O}-\mathrm{H}\left(3419 \mathrm{~cm}^{-1}\right)$ in $\mathrm{SiO}_{2}$ was significantly weakened after the surface modification of $\mathrm{SiO}_{2}$. The new peaks at $2928 \mathrm{~cm}^{-1}$ and $2844 \mathrm{~cm}^{-1}$ were for the stretching vibrations of the methyl and methylene from KH570. Thus, KH570 was successfully grafted onto $\mathrm{SiO}_{2}$. Figure $4 \mathrm{~b}$ shows the FT-IR spectrum of $\mathrm{SMA} / \mathrm{SiO}_{2}$. The peaks at $3061 \mathrm{~cm}^{-1}$ and $3026 \mathrm{~cm}^{-1}$ were for the $\mathrm{C}-\mathrm{H}$ in the benzene ring from St. The peaks at $1603 \mathrm{~cm}^{-1}, 1495 \mathrm{~cm}^{-1}$ and $1452 \mathrm{~cm}^{-1}$ were for the vibrations of the benzene skeleton from St. The peak at $1730 \mathrm{~cm}^{-1}$ was for the stretching vibrations of $\mathrm{C}=\mathrm{O}$, while $1200 \mathrm{~cm}^{-1}$ represented the stretching vibrations of $\mathrm{C}-\mathrm{O}-\mathrm{C}$ from MMA. The peak at $3429 \mathrm{~cm}^{-1}$ represented the stretching vibrations of $\mathrm{N}-\mathrm{H}$ from AM. In addition, the stretching vibrations of $\mathrm{Si}-\mathrm{O}$ and $\mathrm{Si}-\mathrm{O}-\mathrm{Si}$ were located at $1117 \mathrm{~cm}^{-1}$ and $1076 \mathrm{~cm}^{-1}$ respectively. Therefore, the FT-IR spectra show that $\mathrm{SMA} / \mathrm{SiO}_{2}$ was successfully prepared.
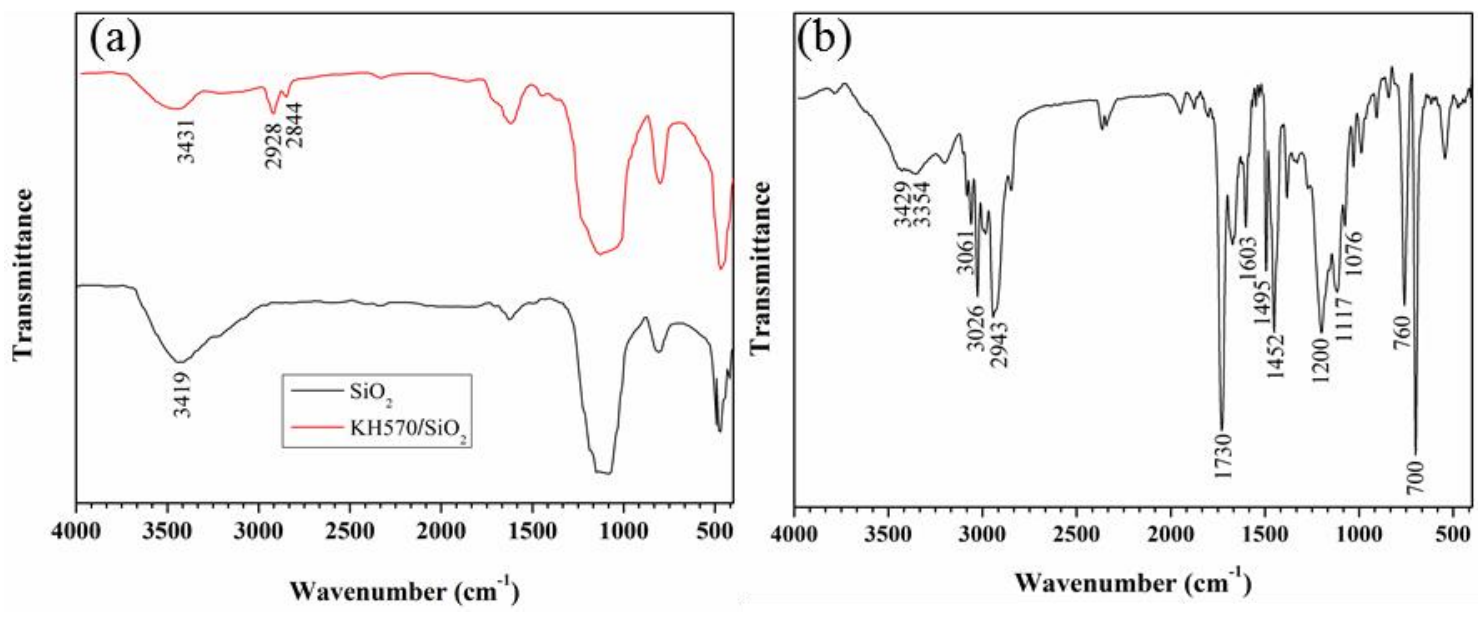

Figure 4. FT-IR spectra of (a) $\mathrm{SiO}_{2}, \mathrm{KH} 570 / \mathrm{SiO}_{2}$ and (b) $\mathrm{SMA} / \mathrm{SiO}_{2}$. 
In order to further characterize the chemical structure of $\mathrm{SMA} / \mathrm{SiO}_{2}$, the ${ }^{1} \mathrm{H}-\mathrm{NMR}$ spectra of $\mathrm{SMA} / \mathrm{SiO}_{2}$ is presented in Figure 5. The peaks corresponding to the protons in the copolymer were labeled. It can be concluded that $\mathrm{St}, \mathrm{MMA}$ and $\mathrm{AM}$ were grafted onto $\mathrm{KH} 570 / \mathrm{SiO}_{2}$. Thus, the chemical structure of $\mathrm{SMA} / \mathrm{SiO}_{2}$ was further confirmed.

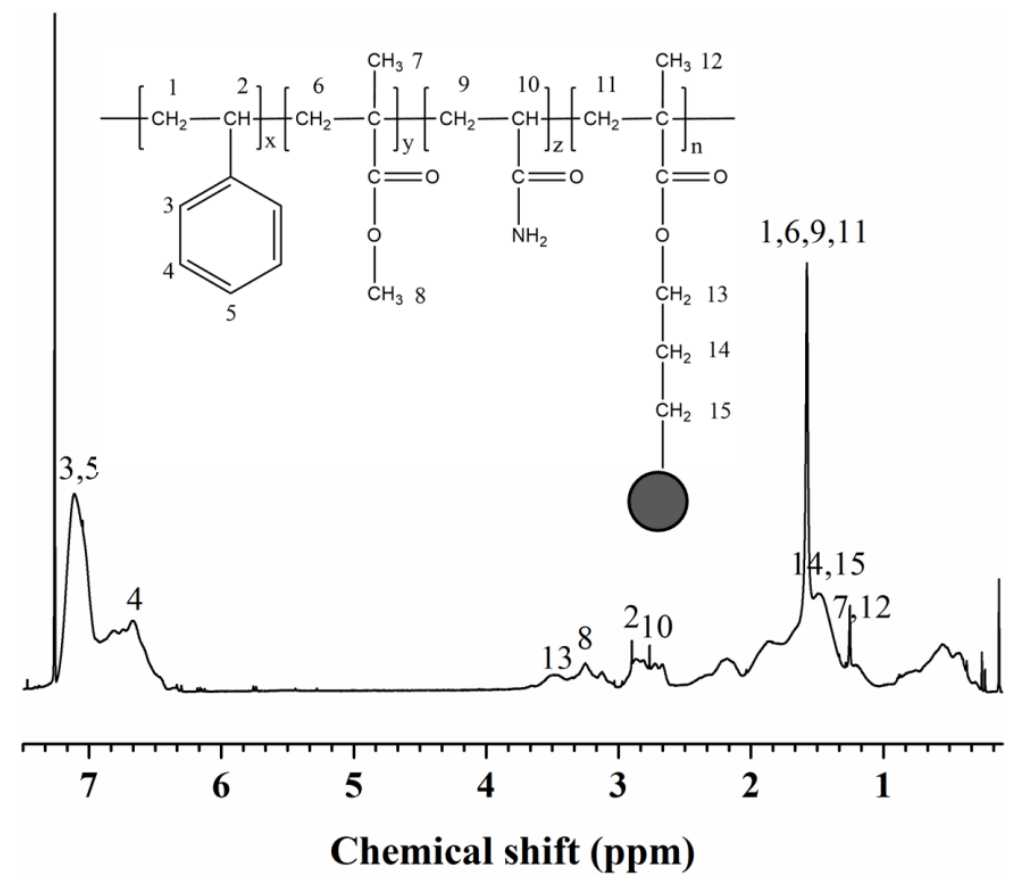

Figure 5. ${ }^{1} \mathrm{H}-\mathrm{NMR}$ spectra of $\mathrm{SMA} / \mathrm{SiO}_{2}$.

The dispersion morphology of $\mathrm{SMA} / \mathrm{SiO}_{2}$ in aqueous solution was observed, and the TEM image is shown in Figure 6. The spherical nanoparticles exhibited good dispersivity in the aqueous solution. In addition, the average particle size of $\mathrm{SMA} / \mathrm{SiO}_{2}$ was about $75 \mathrm{~nm}$, and the particle size distribution was mainly in the range of $50-90 \mathrm{~nm}$.
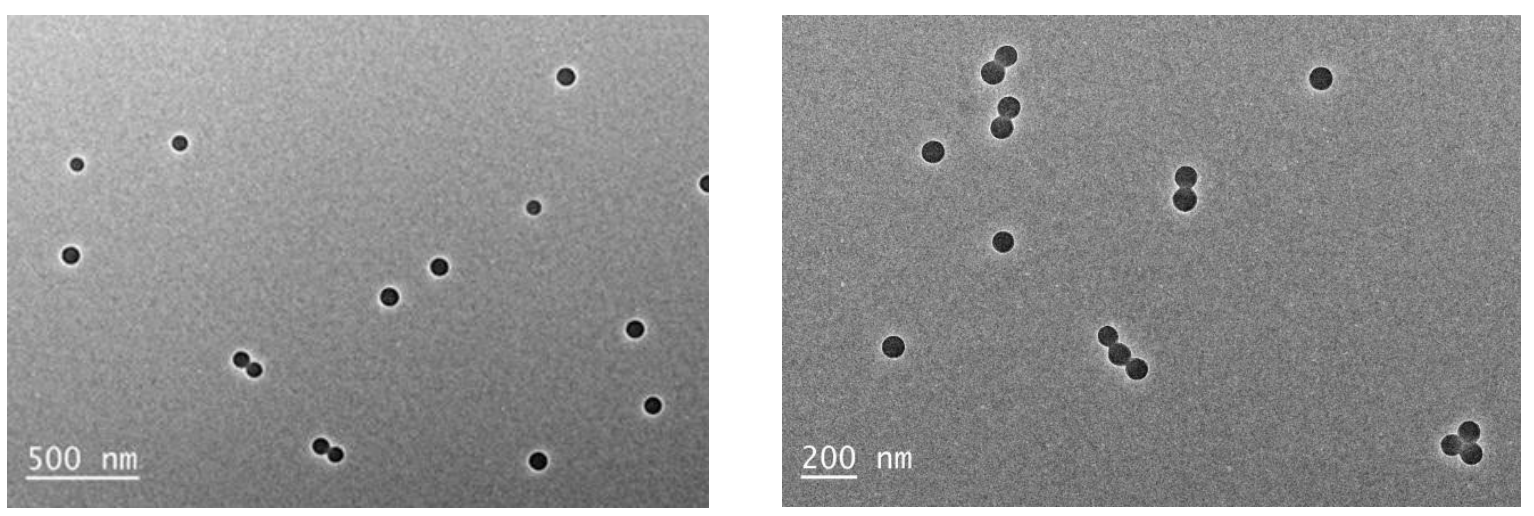

Figure 6. TEM image of $\mathrm{SMA} / \mathrm{SiO}_{2}$.

Figure 7 presents the PSD curves of $\mathrm{SMA} / \mathrm{SiO}_{2}$. The test results showed that the average particle size of $\mathrm{SMA} / \mathrm{SiO}_{2}$ was $72 \mathrm{~nm}$, while the particle size was mainly distributed in the range of 43-122 nm. Due to a few nanoparticles in $\mathrm{SMA} / \mathrm{SiO}_{2}$ agglomerated, the larger particles were found in the PSD test results. Overall, the PSD test results corresponded with the TEM characterization results. The nanoscale diameter of $\mathrm{SMA} / \mathrm{SiO}_{2}$ was further confirmed. It could be inferred that $\mathrm{SMA} / \mathrm{SiO}_{2}$ was able to plug the shale pores and cracks in nano-scale. 


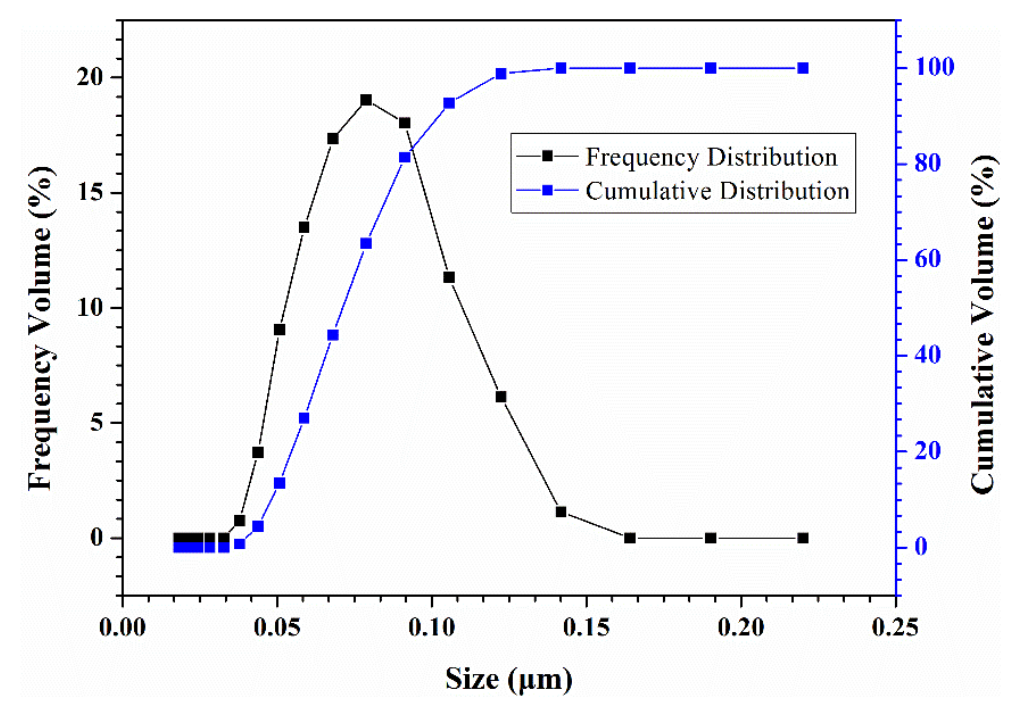

Figure 7. PSD curves of $\mathrm{SMA} / \mathrm{SiO}_{2}$.

Figure 8 shows the thermogravimetric curves of $\mathrm{SMA} / \mathrm{SiO}_{2}$. The weight loss was less than $0.3 \%$ for $\mathrm{SMA} / \mathrm{SiO}_{2}$ below the temperature of $120^{\circ} \mathrm{C}$ due to the solvent evaporation. No significant weight loss was observed before the temperature reached $390^{\circ} \mathrm{C}$. Thermal stability is essential for plugging agents since WBMs withstand high-temperature stratum conditions. Through the results of TGA analysis, good high-temperature resistance of $\mathrm{SMA} / \mathrm{SiO}_{2}$ was confirmed.

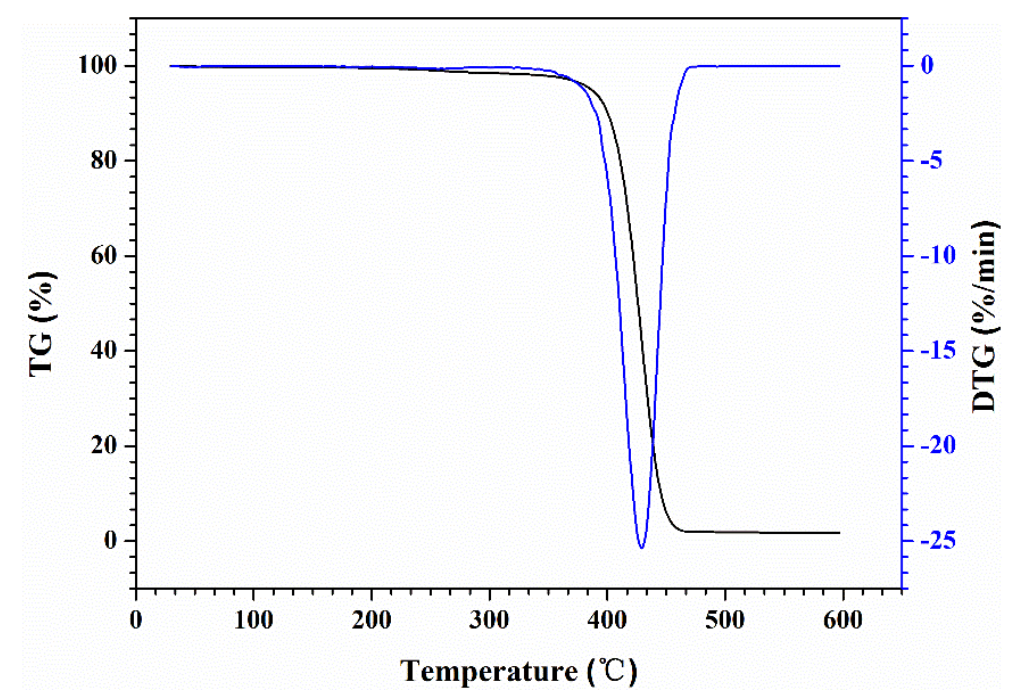

Figure 8. TGA (thermogravimetric analysis) curves of $\mathrm{SMA} / \mathrm{SiO}_{2}$.

\subsection{Pressure Transmission Test}

Figure 9 presents the downstream pressure change with time when the shale cores interacted with different test fluids. As shown in Figure 9, the pressure transmission rate of the shale cores was so fast that the downstream and upstream pressures were basically the same after $40 \mathrm{~min}$. For the base fluid, a lower growth rate of the downstream pressure was observed, and it took about $128 \mathrm{~min}$ to achieve the equilibrium for the downstream and upstream pressures. For the base fluid containing $1 \% \mathrm{SiO}_{2}$, it took about $183 \mathrm{~min}$ to achieve the equilibrium for the downstream and upstream pressures. For the base fluid containing $1 \% \mathrm{SMA}_{\mathrm{SiO}}$, it took about $255 \mathrm{~min}$ to achieve the equilibrium, which was significantly longer than the penetration times of the shale cores and the base fluid containing $1 \%$ $\mathrm{SiO}_{2}$. Thus, $\mathrm{SMA} / \mathrm{SiO}_{2}$ played a notable role in slowing down the shale pressure transmission rate. The plugging capacity of $\mathrm{SMA} / \mathrm{SiO}_{2}$ was further evaluated through analyzing the shale permeability 
change. The permeability of the shale cores before being plugged was $1.68 \times 10^{-6} \mu \mathrm{m}^{2}$. After being treated by the base fluid and the base fluid containing $1 \% \mathrm{SiO}_{2}$, the permeability was decreased to $1.09 \times 10^{-7} \mu^{2}$ and $8.00 \times 10^{-8} \mu^{2}$ respectively. Most noteworthy, after being plugged by the base fluid containing $1 \% \mathrm{SMA} / \mathrm{SiO}_{2}$, the permeability was significantly reduced to $6.45 \times 10^{-8} \mu \mathrm{m}^{2}$. Therefore, $\mathrm{SMA} / \mathrm{SiO}_{2}$ possessed the capacity to seal the nano-scale pores and fractures, and a lower pressure transmission rate and shale permeability were observed after interact with $\mathrm{SMA} / \mathrm{SiO}_{2}$.

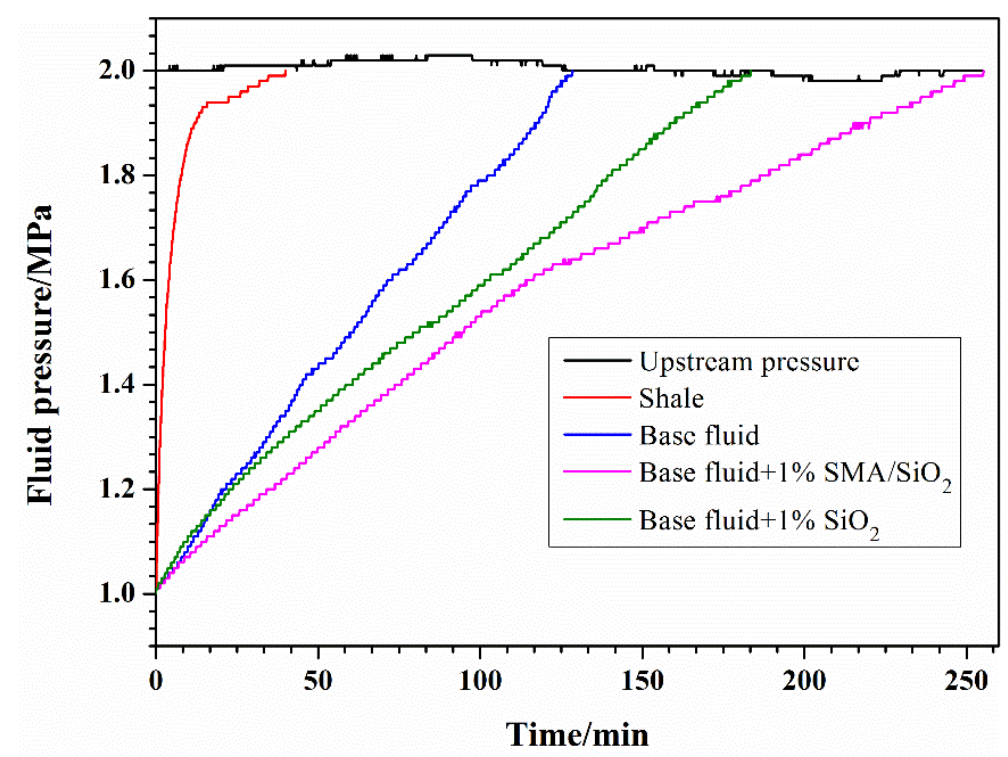

Figure 9. Pressure transmission experiment curves.

The SEM images of the shale cores after the pressure transmission experiments are shown in Figure 10. As shown in Figure 10a, a lot of pores and fractures developed in the shale cores and it can be inferred that the diameter of shale pores and the width of shale fractures were mainly distributed between $50-500 \mathrm{~nm}$. These pores and fractures were effectively plugged after interaction with $\mathrm{SMA} / \mathrm{SiO}_{2}$ in the base fluid (Figure 10b). After being plugged, the core surface changed to be smooth and dense, and an isolation layer was formed on it. As a result, the shale permeability was significantly reduced and the plugging capacity of $\mathrm{SMA} / \mathrm{SiO}_{2}$ was excellent.

(a)

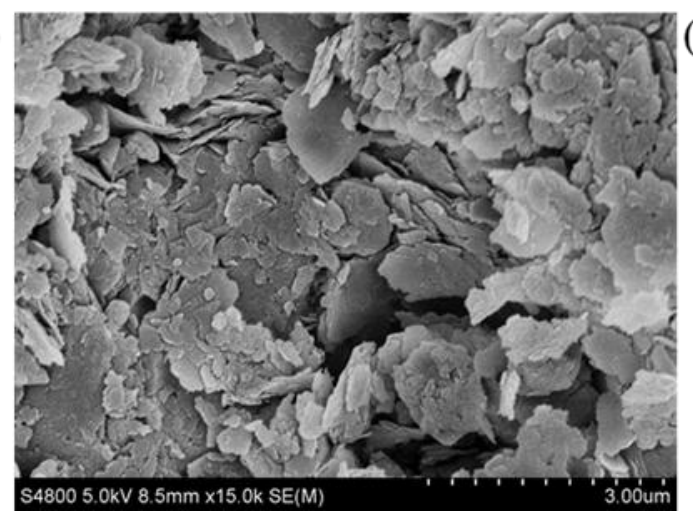

(b)

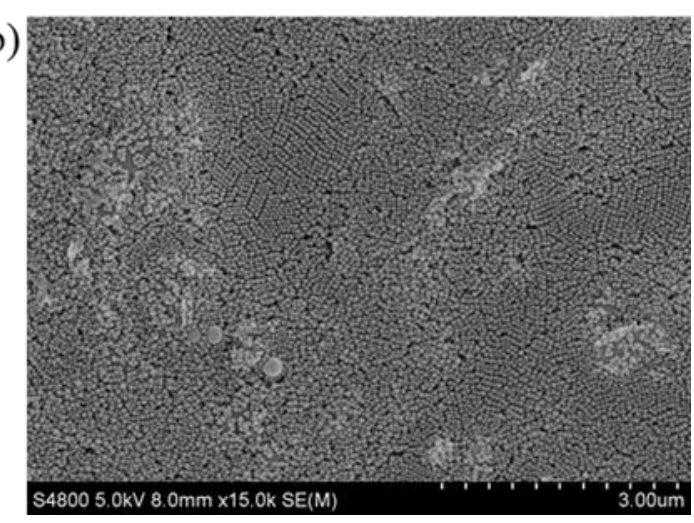

Figure 10. SEM images of the shale cores (a) before interaction and (b) after interaction with the base fluid containing $1 \% \mathrm{SMA} / \mathrm{SiO}_{2}$.

\subsection{Pore Structure Characterization of Shale}

The plugging capacity of $\mathrm{SMA} / \mathrm{SiO}_{2}$ was further determined through BET analysis, and the surface area and pore volume of shale samples were used as evaluation parameters. As presented in 
Figure 11, the surface area of original shale without treatment was $15.51 \mathrm{~m}^{2} / \mathrm{g}$, with a pore volume of $0.02541 \mathrm{~cm}^{3} / \mathrm{g}$. After being soaked in deionized water, the surface area and pore volume of shale were increased to $19.64 \mathrm{~m}^{2} / \mathrm{g}$ and $0.03107 \mathrm{~cm}^{3} / \mathrm{g}$ respectively. The large increase in the surface area and pore volume indicated that water strongly interacted with shale, resulting in bigger pores and fractures in shale samples. The hydration and capillary effect are essential factors leading to the pores and fractures propagation in shale samples [47]. However, after being soaked in $1.0 \% \mathrm{SiO}_{2}$ solutions, the surface area and pore volume of shale were decreased to $13.42 \mathrm{~m}^{2} / \mathrm{g}$ and $0.02407 \mathrm{~cm}^{3} / \mathrm{g}$ respectively. In especial, a significant decrease was observed after being soaked in $1.0 \% \mathrm{SMA} / \mathrm{SiO}_{2}$ solutions, and the surface area and pore volume were reduced to $10.33 \mathrm{~m}^{2} / \mathrm{g}$ and $0.02186 \mathrm{~cm}^{3} / \mathrm{g}$ respectively. Results indicated that $\mathrm{SMA} / \mathrm{SiO}_{2}$ was able to effectively plug the shale pores and fractures, and thus prevent water invading into shale samples.
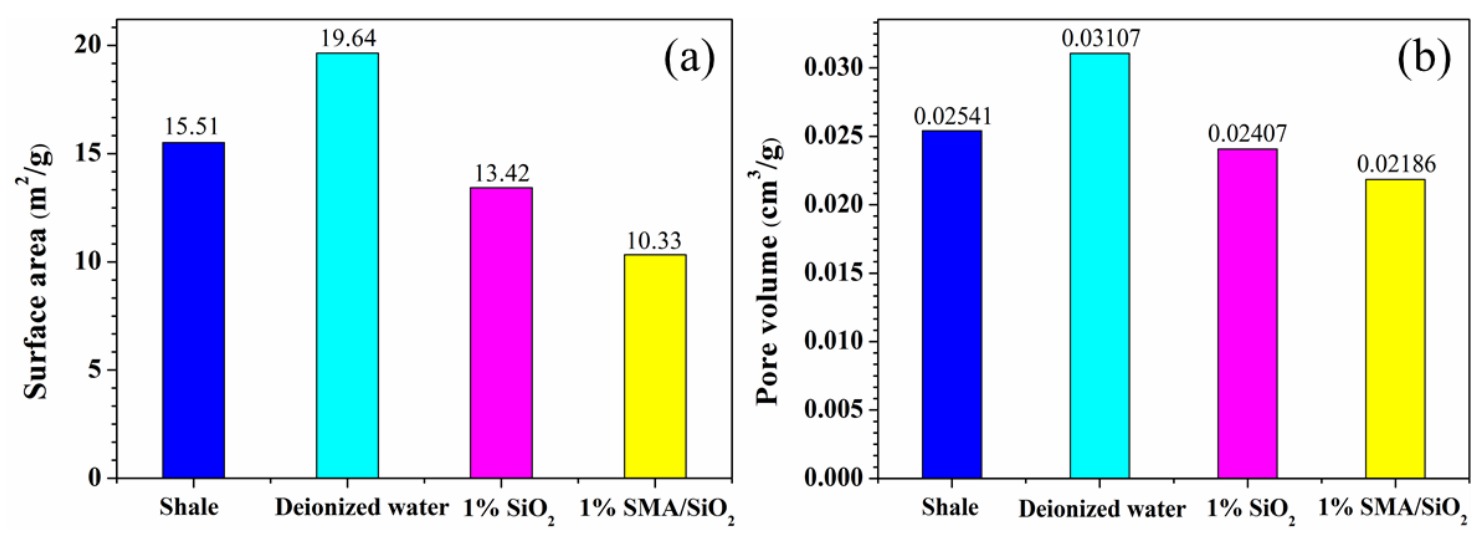

Figure 11. (a) The surface area and (b) pore volume of shale cores after soaked in different fluids.

\subsection{Rolling Dispersion Experiment}

In order to evaluate the hydration inhibition property of $\mathrm{SMA} / \mathrm{SiO}_{2}, \mathrm{KCl}$ and $\mathrm{JHC}$ as good shale inhibitors were used for comparison. The results of the rolling dispersion experiment were presented in Figure 12. The rolling recovery rate of shale in deionized water was $40.2 \%$, demonstrating that the shale samples possessed strong hydration dispersion ability. This could be attributed to the high content of smectite in shale samples. With the increase in $\mathrm{SMA} / \mathrm{SiO}_{2}$ dosage, the recovery rate was enhanced significantly. When the concentration of $\mathrm{SMA} / \mathrm{SiO}_{2}$ was $2.0 \%$, the shale recovery rate was up to $93.6 \%$. In addition, compared with $\mathrm{KCl}, \mathrm{JHC}$ and $\mathrm{SiO}_{2}$, the higher recovery rates were observed in $\mathrm{SMA} / \mathrm{SiO}_{2}$ solutions at various concentrations. Therefore, $\mathrm{SMA} / \mathrm{SiO}_{2}$ was able to reduce the tendency of shale dispersion and exhibited strong hydration inhibition. The results can be explained by the shale hydration inhibition mechanism of amphiphilic polymer [41]. The hydrophilic segments in $\mathrm{SMA} / \mathrm{SiO}_{2}$ were capable of enhancing the adsorption between $\mathrm{SMA} / \mathrm{SiO}_{2}$ and the shale, because shale is hydrophilic. Thus, $\mathrm{SMA} / \mathrm{SiO}_{2}$ could occupy the adsorption sites in shale instead of water. As a result, the hydrophobic segments provided by St and MMA in the amphiphilic polymer could greatly change the wettability of shale. The shale surface became more hydrophobic after adsorbed by $\mathrm{SMA} / \mathrm{SiO}_{2}$, which was in favor of preventing the water invading into the shale. Therefore, the excellent hydration inhibition of $\mathrm{SMA} / \mathrm{SiO}_{2}$ was achieved. 


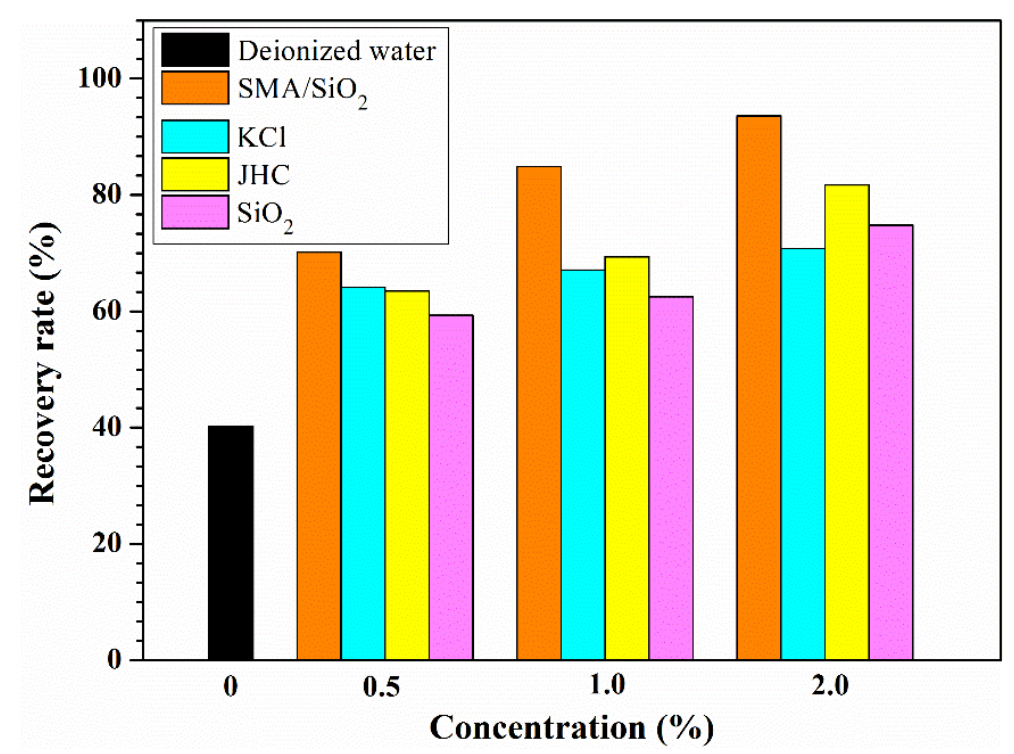

Figure 12. The results of rolling dispersion experiment.

\subsection{Contact Angle Test Results}

The influence of $\mathrm{SMA} / \mathrm{SiO}_{2}$ on the wettability of the shale surface was measured, and the test results were shown in Figure 13. The original shale was strongly hydrophilic with a contact angle of $34.4^{\circ}$. With the increase of $\mathrm{SMA} / \mathrm{SiO}_{2}$ concentration, the contact angle was gradually enlarged. After treatment with $2.0 \% \mathrm{SMA} / \mathrm{SiO}_{2}$ solutions, the contact angle was increased to $72.7^{\circ}$. Thus, a more hydrophobic shale surface would be formed after treatment with $\mathrm{SMA} / \mathrm{SiO}_{2}$. Less water intrusion into the shale due to the hydrophobic surface was more conducive to the shale stability [48].

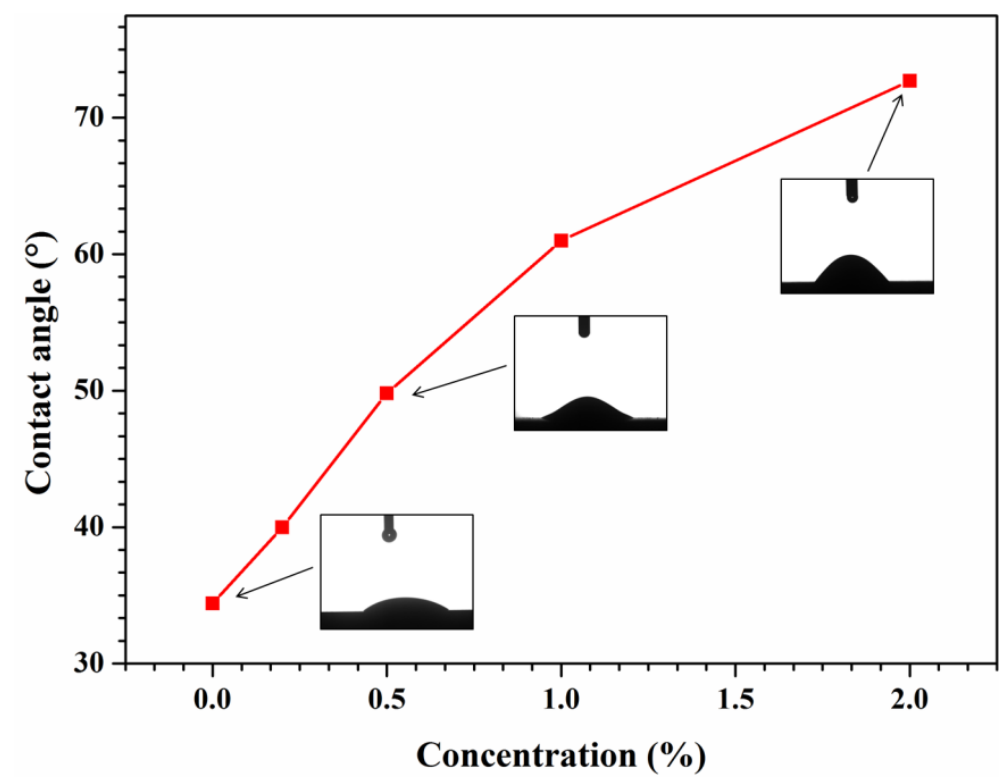

Figure 13. The results of contact angle test.

\subsection{Probable Shale Stabilization Mechanism}

A possible shale stabilization mechanism of $\mathrm{SMA} / \mathrm{SiO}_{2}$ could be summarized in view of the research findings from this work and some previous researches. Under the drilling pressure differential, the nanoparticles in $\mathrm{SMA} / \mathrm{SiO}_{2}$ are pressed into the nanopores and cracks in the shale. A plugging layer is formed on the shale, resulting in a lower pressure transmission rate and shale permeability. 
Thus, the excellent plugging performance of $\mathrm{SMA} / \mathrm{SiO}_{2}$ is achieved. In addition, the hydrophilic segments in $\mathrm{SMA} / \mathrm{SiO}_{2}$ can enhance the adsorption between $\mathrm{SMA} / \mathrm{SiO}_{2}$ and the shale. After being adsorbed by $\mathrm{SMA} / \mathrm{SiO}_{2}$, a more hydrophobic shale surface will be obtained due to the hydrophobic segments in $\mathrm{SMA} / \mathrm{SiO}_{2}$, which can further prevent the water invading into the shale. As a result, $\mathrm{SMA} / \mathrm{SiO}_{2}$ exhibits good hydration inhibition. Overall, the novel shale stabilizer $\mathrm{SMA} / \mathrm{SiO}_{2}$ has the advantages of both physical plugging and chemical inhibition.

In addition, in order to further optimize the molecular structure of $\mathrm{SMA} / \mathrm{SiO}_{2}$ and explore its shale stabilization mechanism, more detailed statistical analysis and refined structural characterization will be carried out in our future work $[49,50]$.

\subsection{Compatible Test}

Table 2 presents the effect of $\mathrm{SMA} / \mathrm{SiO}_{2}$ on the rheological and filtration control properties of the WBMs. After being hot-rolled at $120^{\circ} \mathrm{C}$ for $16 \mathrm{~h}, \mathrm{SMA} / \mathrm{SiO}_{2}$ only created slight variations on the rheological parameters of the WBMs. In addition, the fluid loss of the WBMs with $2.0 \% \mathrm{SMA} / \mathrm{SiO}_{2}$ was decreased from 8.2 to $6.4 \mathrm{~mL}$, indicating a significant filtration control performance of $\mathrm{SMA} / \mathrm{SiO}_{2}$.

Table 2. Effect of $\mathrm{SMA} / \mathrm{SiO}_{2}$ on the rheological and filtration control properties of the WBMs (water-based muds).

\begin{tabular}{ccc}
\hline Parameter & Before adding SMA/SiO & After adding $\mathbf{2 . 0} \% \mathbf{S M A} / \mathbf{S i O}_{\mathbf{2}}$ \\
\hline$\theta$ at $600 \mathrm{rpm}\left(\mathrm{lbf} / 100 \mathrm{ft}^{2}\right)$ & 70 & 74 \\
$\theta$ at $300 \mathrm{rpm}\left(\mathrm{lbf} / 100 \mathrm{ft}^{2}\right)$ & 44 & 46 \\
$\mathrm{AV}(\mathrm{mPa} . \mathrm{s})$ & 35 & 37 \\
$\mathrm{PV}(\mathrm{mPa} . \mathrm{s})$ & 26 & 28 \\
YP $(\mathrm{Pa})$ & 9 & 9 \\
$\mathrm{YP} / \mathrm{PV}$ & 0.35 & 0.32 \\
$\mathrm{FL}_{\mathrm{API}}(\mathrm{mL})$ & 8.2 & 6.4 \\
\hline
\end{tabular}

\section{Conclusions}

The following conclusions can be drawn from the current work:

(1) An amphiphilic polymer/nano-silica composite $\left(\mathrm{SMA} / \mathrm{SiO}_{2}\right)$ was prepared and characterized as a novel shale stabilizer for water-based muds. The novel shale stabilizer $\mathrm{SMA} / \mathrm{SiO}_{2}$ with spherical structure mainly distributed in the range of 43-122 $\mathrm{nm}$ and exhibited good high-temperature resistance.

(2) $\mathrm{SMA} / \mathrm{SiO}_{2}$ could effectively plug the shale pores and cracks, and slow down the pressure transmission rate. After being plugged by $\mathrm{SMA} / \mathrm{SiO}_{2}$, the core surface changed to be smooth and dense, and an isolation layer was formed on it. In addition, a significant decrease of the shale surface area and pore volume were observed after treatment by $\mathrm{SMA} / \mathrm{SiO}_{2}$.

(3) $\mathrm{SMA} / \mathrm{SiO}_{2}$ also showed good hydration inhibition, which was better than $\mathrm{KCl}$ and JHC. The hydrophilic segments in $\mathrm{SMA} / \mathrm{SiO}_{2}$ could enhance the adsorption between $\mathrm{SMA} / \mathrm{SiO}_{2}$ and the shale, and thus the hydrophobic segments could change the shale surface to become more hydrophobic after being adsorbed by $\mathrm{SMA} / \mathrm{SiO}_{2}$, which was in favor of further preventing the water invading into the shale.

(4) The excellent performance of physical plugging and chemical inhibition were achieved, and $\mathrm{SMA} / \mathrm{SiO}_{2}$ was expected to be a novel shale stabilizer to solve shale instability problems.

Author Contributions: Z.Q. and J.X. conceived and designed the experiments; J.X. and X.Z. synthesized the amphiphilic polymer/nano-silica composite; P.Y. and T.M. performed the evaluation experiments; X.Z., H.Z. and W.H. analyzed the data; and Z.Q. and J.X. wrote the paper.

Acknowledgments: This work was supported by the National Natural Science Foundation of China (U1562101), the National Science and Technology Major Project of China (2016ZX05020-004), Shandong Provincial Natural Science Foundation (ZR2017BEE036) and the Fundamental Research Funds for the Central Universities (16CX06034A).

Conflicts of Interest: The authors declare no conflict of interest. 


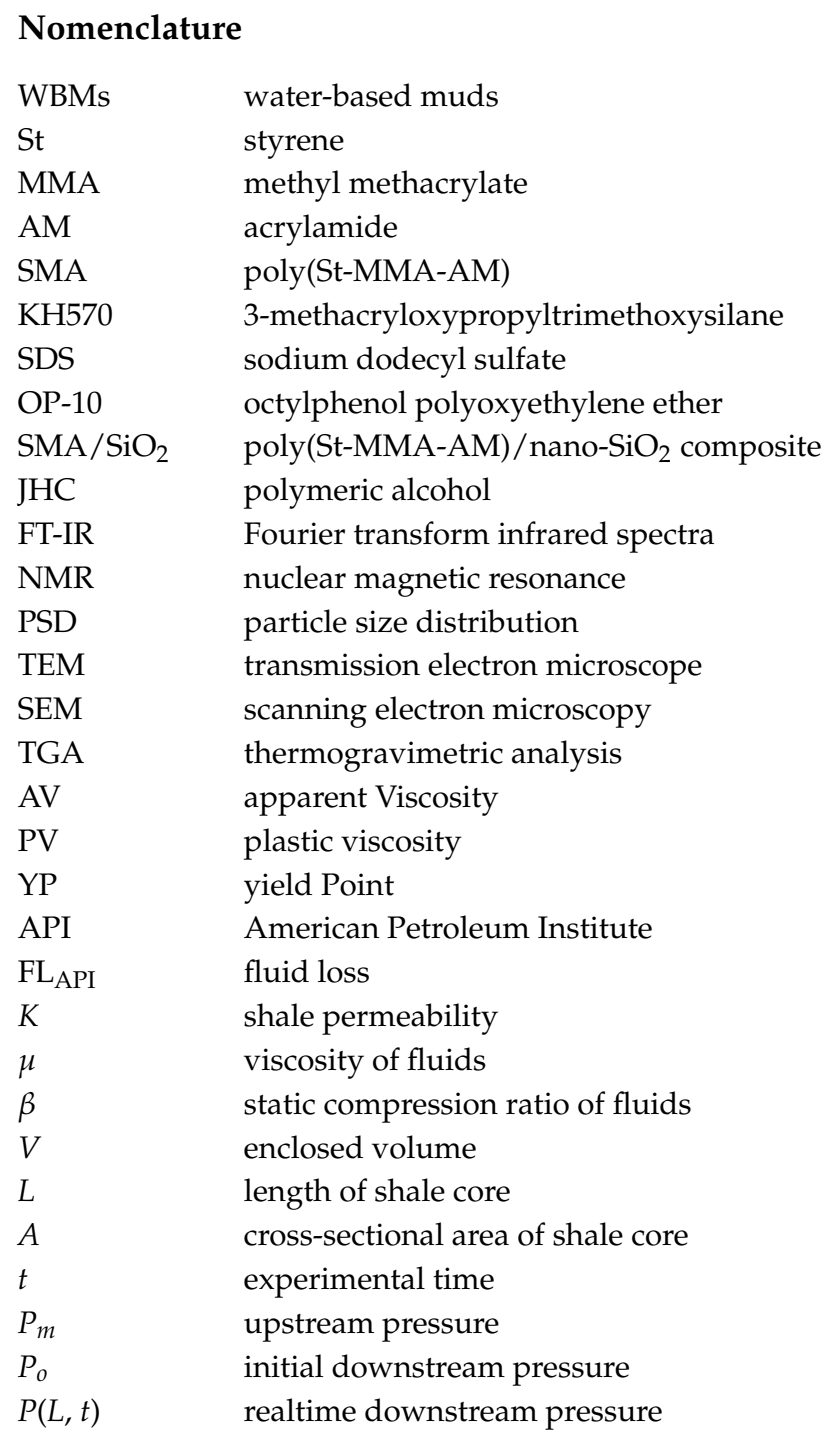

\section{References}

1. Razali, S.Z.; Yunus, R.; Rashid, S.A.; Lim, H.N.; Jan, B.M. Review of biodegradable synthetic-based drilling fluid: progression, performance and future prospect. Renew. Sustain. Energy Rev. 2018, 90, 171-186. [CrossRef]

2. Zhao, X.; Qiu, Z.; Huang, W.; Wang, M. Mechanism and method for controlling low-temperature rheology of water-based drilling fluids in deepwater drilling. J. Pet. Sci. Eng. 2017, 154, 405-416. [CrossRef]

3. Xu, J.; Qiu, Z.; Zhao, X.; Mou, T.; Zhong, H.; Huang, W. A polymer microsphere emulsion as a high-performance shale stabilizer for water-based drilling fluids. RSC Adv. 2018, 8, 20852-20861. [CrossRef]

4. Xie, B.; Liu, X. Thermo-thickening behavior of LCST-based copolymer viscosifier for water-based drilling fluids. J. Pet. Sci. Eng. 2017, 154, 244-251. [CrossRef]

5. Song, K.; Wu, Q.; Li, M.; Ren, S.; Dong, L.; Zhang, X.; Kojima, Y. Water-based bentonite drilling fluids modified by novel biopolymer for minimizing fluid loss and formation damage. Colloids Surf. A 2016, 507, 58-66. [CrossRef]

6. Wang, L.L.; Zhang, G.Q.; Hallais, S.; Tanguy, A.; Yang, D.S. Swelling of shales: A multiscale experimental investigation. Energy Fuels 2017, 31, 10442-10451. [CrossRef]

7. Dehghanpour, H.; Zubair, H.A.; Chhabra, A.; Ullah, A. Liquid intake of organic shales. Energy Fuels 2012, 26, 5750-5758. [CrossRef]

8. Chamkalani, A.; Zendehboudi, S.; Amani, M.; Chamkalani, R.; James, L.; Dusseault, M. Pattern recognition insight into drilling optimization of shaly formations. J. Pet. Sci. Eng. 2017, 156, 322-339. [CrossRef] 
9. Zhao, H.; Firoozabadi, A. Sorption Hysteresis of Light Hydrocarbons and Carbon Dioxide in Shale and Kerogen. Sci. Rep. 2017, 7, 16209. [CrossRef] [PubMed]

10. Zhang, L.; Kou, Z.; Wang, H.; Zhao, Y.; Dejam, M.; Guo, J.; Du, J. Performance analysis for a model of a multi-wing hydraulically fractured vertical well in a coalbed methane gas reservoir. J. Pet. Sci. Eng. 2018, 166, 104-120. [CrossRef]

11. Jin, Z.; Firoozabadi, A. Phase Behavior and Flow in Shale Nanopores from Molecular Simulations. Fluid Phase Equilib. 2016, 430, 156-168. [CrossRef]

12. Dejam, M.; Hassanzadeh, H.; Chen, Z. Semi-analytical solution for pressure transient analysis of a hydraulically fractured vertical well in a bounded dual-porosity reservoir. J. Hydrol. 2018, 565, 289-301. [CrossRef]

13. Liu, K.; Ostadhassan, M. Microstructural and geomechanical analysis of Bakken shale at nanoscale. J. Pet. Sci. Eng. 2017, 153, 133-144. [CrossRef]

14. Ma, F.; Pu, X.; Wang, B.; Li, J.; Cao, C. Preparation and evaluation of polyampholyte inhibitor DAM. RSC Adv. 2017, 7, 49320-49328. [CrossRef]

15. Zhang, S.; Sheng, J.J.; Shen, Z. Effect of hydration on fractures and permeabilities in Mancos, Eagleford, Barnette and Marcellus shale cores under compressive stress conditions. J. Pet. Sci. Eng. 2017, 156, 917-926. [CrossRef]

16. Sun, Z.; Shi, J.; Wu, K.; Xu, B.; Zhang, T.; Chang, Y.; Li, X. Transport capacity of gas confined in nanoporous ultra-tight gas reservoirs with real gas effect and water storage mechanisms coupling. Int. J. Heat Mass Transf. 2018, 126, 1007-1018. [CrossRef]

17. Dejam, M.; Hassanzadeh, H.; Chen, Z. Pre-Darcy flow in porous media. Water Resour. Res. 2017, 53, 8187-8210. [CrossRef]

18. An, Y.; Jiang, G.; Qi, Y.; Huang, X.; He, S. High-performance shale plugging agent based on chemically modified grapheme. J. Nat. Gas Sci. Eng. 2016, 32, 347-355.

19. Xu, J.; Qiu, Z.; Huang, W.; Zhao, X. Preparation and performance properties of polymer latex SDNL in water-based drilling fluids for drilling troublesome shale formations. J. Nat. Gas Sci. Eng. 2017, 37, 462-470. [CrossRef]

20. Steiger, R.P.; Leung, P.K. Quantitative determination of the mechanical properties of shales. SPE Drill. Complet. 1992, 7, 181-185. [CrossRef]

21. Hassani, S.S.; Amrollahi, A.; Rashidi, A.; Soleymani, M.; Rayatdoost, S. The effect of nanoparticles on the heat transfer properties of drilling fluids. J. Pet. Sci. Eng. 2016, 146, 183-190. [CrossRef]

22. Lau, H.C.; Yu, M.; Nguyen, Q.P. Nanotechnology for oilfield applications: Challenges and impact. J. Pet. Sci. Eng. 2017, 157, 1160-1169. [CrossRef]

23. Li, Y.; Dai, C.; Zhou, H.; Wang, X.; Lv, W.; Wu, Y. A novel nanofluid based on fluorescent carbon nanoparticles for enhanced oil recovery. Ind. Eng. Chem. Res. 2017, 56, 12464-12470. [CrossRef]

24. Zoveidavianpoor, M.; Samsuri, A. The use of nano-sized tapioca starch as a natural water-soluble polymer for filtration control in water-based drilling muds. J. Nat. Gas Sci. Eng. 2016, 34, 832-840. [CrossRef]

25. William, J.K.; Ponmani, M.S.; Samuel, R.; Nagarajan, R.; Sangwai, J.S. Effect of CuO and ZnO nanofluids in xanthan gum on thermal, electrical and high pressure rheology of water-based drilling fluids. J. Pet. Sci. Eng. 2014, 117, 15-27. [CrossRef]

26. An, Y.; Jiang, G.; Qi, Y.; Ge, Q.; Zhang, L.; Ren, Y. Synthesis of nano-plugging agent based on AM/AMPS/NVP terpolymer. J. Pet. Sci. Eng. 2015, 135, 505-514. [CrossRef]

27. Cai, J.; Chenevert, M.E.; Sharma, M.M.; Friedheim, J.E. Decreasing water invasion into atoka shale using nonmodified silica nanoparticles. SPE Drill. Complet. 2012, 27, 103-112. [CrossRef]

28. Jain, R.; Mahto, V.; Sharma, V.P. Evaluation of polyacrylamide-grafted-polyethylene glycol/silica nanocomposite as potential additive in water based drilling mud for reactive shale formation. J. Nat. Gas Sci. Eng. 2015, 26, 526-537. [CrossRef]

29. Kosynkin, D.V.; Ceriotti, G.; Wilson, K.C.; Lomeda, J.R.; Scorsone, J.T.; Patel, A.D. Graphene oxide as a high-performance fluid-loss-control additive in water-based drilling fluids. ACS Appl. Mater. Interfaces 2012, 4, 222-227. [CrossRef] [PubMed]

30. Xu, J.; Qiu, Z.; Zhao, X.; Zhang, Y.; Li, G.; Huang, W. Application of nano-polymer emulsion for inhibiting shale self-imbibition in water-based drilling fluids. J. Surfactants Deterg. 2018, 21, 155-164. [CrossRef] 
31. Liu, J.; Qiu, Z.; Huang, W. Novel latex particles and aluminum complexes as potential shale stabilizers in water-based drilling fluids. J. Pet. Sci. Eng. 2015, 135, 433-441. [CrossRef]

32. Seright, R.S. How Much Polymer Should Be Injected During a Polymer Flood? Review of Previous and Current Practices. Soc. Pet. Eng. J. 2018, 22, 1-18.

33. Amirian, E.; Dejam, M.; Chen, Z. Performance forecasting for polymer flooding in heavy oil reservoirs. Fuel 2018, 216, 83-100. [CrossRef]

34. Saboorian-Jooybari, H.; Dejam, M.; Chen, Z. Heavy oil polymer flooding from laboratory core floods to pilot tests and field applications: Half-century studies. J. Pet. Sci. Eng. 2016, 142, 85-100. [CrossRef]

35. Mashayekhizadeh, V.; Kord, S.; Dejam, M. EOR potential within Iran. Spec. Top. Rev. Porous Media 2014, 5, 325-354. [CrossRef]

36. Mao, H.; Qiu, Z.; Shen, Z.; Huang, W. Hydrophobic associated polymer based silica nano particles composite with core-shell structure as a filtrate reducer for drilling fluid at utra-high temperature. J. Pet. Sci. Eng. 2015, 129, 1-14. [CrossRef]

37. Xu, J.; Qiu, Z.; Zhao, X.; Zhong, H.; Li, G.; Huang, W. Synthesis and characterization of shale stabilizer based on polyethylene glycol grafted nano-silica composite in water-based drilling fluids. J. Pet. Sci. Eng. 2018, 163, 371-377. [CrossRef]

38. Ferreira, C.C.; Teixeira, G.T.; Lachter, E.R.; Nascimento, R.S.V. Partially hydrophobized hyperbranched polyglycerols as non-ionic reactive shale inhibitors for water-based drilling fluids. Appl. Clay Sci. 2016, 132, 122-132. [CrossRef]

39. Barati, P.; Keshtkar, S.; Aghajafari, A.; Shahbazi, K.; Momeni, A. Inhibition performance and mechanism of horsetail extract as shale stabilizer. Pet. Explor. Dev. 2016, 43, 522-527. [CrossRef]

40. Zhong, H.; Qiu, Z.; Sun, D.; Zhang, D.; Huang, W. Inhibitive properties comparison of different polyetheramines in water-based drilling fluid. J. Nat. Gas Sci. Eng. 2015, 26, 99-107. [CrossRef]

41. Zhang, X.; Jiang, G.; Dong, T.; Wang, L.; Li, X.; Wang, G. An amphoteric polymer as a shale borehole stabilizer in water-based drilling fluids. J. Pet. Sci. Eng. 2018, 170, 112-120. [CrossRef]

42. Xu, J.; Qiu, Z.; Zhao, X.; Huang, W. Hydrophobic modified polymer based silica nanocomposite for improving shale stability in water-based drilling fluids. J. Pet. Sci. Eng. 2017, 153, 325-330. [CrossRef]

43. Xu, J.F.; Qiu, Z.S.; Lyu, K.H. Pressure transmission testing technology and simulation equipment for hydramechanics coupling of shale. Acta Pet. Sin. 2005, 27, 26-27.

44. Xu, J.F.; Qiu, Z.S. Simulation test equipment of coupled hydra-mechanics of shales. J. China Univ. Pet. (Ed. Nat. Sci.) 2006, 30, 63-66.

45. Zhang, P.; Lu, S.; Li, J.; Xue, H.; Li, W.; Zhang, P. Characterization of shale pore system: A case study of Paleogene Xin'gouzui Formation in the Jianghan basin, China. Mar. Pet. Geol. 2017, 79, 321-334. [CrossRef]

46. Liu, K.; Ostadhassan, M.; Kong, L. Multifractal characteristics of Longmaxi Shale pore structures by $\mathrm{N}_{2}$ adsorption: A model comparison. J. Pet. Sci. Eng. 2018, 168, 330-341. [CrossRef]

47. Liang, L.; Xiong, J.; Liu, X. Experimental study on crack propagation in shale formations considering hydration and wettability. J. Nat. Gas Sci. Eng. 2015, 23, 492-499. [CrossRef]

48. Huang, W.; Li, X.; Qiu, Z.; Jia, J.; Wang, Y.; Li, X. Inhibiting the surface hydration of shale formation using preferred surfactant compound of polyamine and twelve alkyl two hydroxyethyl amine oxide for drilling. J. Pet. Sci. Eng. 2017, 159, 791-798. [CrossRef]

49. Hamdia, K.M.; Silani, M.; Zhuang, X.; He, P.; Rabczuk, T. Stochastic analysis of the fracture toughness of polymeric nanoparticle composites using polynomial chaos expansions. Int. J. Fract. 2017, 206, $215-227$. [CrossRef]

50. Vu-Bac, N.; Lahmer, T.; Zhuang, X.; Nguyen-Thoi, T.; Rabczuk, T. A software framework for probabilistic sensitivity analysis for computationally expensive models. Adv. Eng. Softw. 2016, 100, 19-31. [CrossRef]

(C) 2018 by the authors. Licensee MDPI, Basel, Switzerland. This article is an open access article distributed under the terms and conditions of the Creative Commons Attribution (CC BY) license (http:// creativecommons.org/licenses/by/4.0/). 